А. Л. Ганзюк, кандидат технічних наук, директор,

Хмельницький науково-дослідний

експертно-криміналістичний центр МВС Украйни, м. Хмельницький

ORCID: https://orcid.org/0000-0003-3767-9427

А. І. Гордєєв, доктор технічних наук, професор, бахівеиь 1-ї категорії відділу забезпечення діяльності,

Хмельницький науково-дослідний

експертно-криміналістичний иентр МВС Украӥни,

м. Хмельницький

ORCID: https://orcid.org/0000-0003-4494-4348

Є. В. Сич, завідувач відділу автотехнічних досліджень

та криміналістичного дослідження транспортних засобів,

Хмельницький науково-дослідний

експертно-криміналістичний иентр МВС Украӥни,

м. Хмельницькиц̆

ORCID: https://orcid.org/ 0000-0002-0600-2766

\title{
ОБГРУНТУВАННЯ ПАРАМЕТРІВ КОНСТРУКЦІЇ ПРИСТРОЮ ДЛЯ МАГНІТНО-ПОРОШКОВОЇ ДЕФЕКТОСКОПІЇ НОМЕРІВ ВУЗЛІВ ТРАНСПОРТНИХ ЗАСОБІВ
}

\begin{abstract}
Метою статті $є$ обгрунтування конструктивних параметрів і працездатності пристрою для експертних досліджень 3 виявлення прихованих дефектів структури поверхневого шару металу та встановлення наявності перебивання номерних знаків, вварювання окремих ділянок або відсутності таких пошкоджень на поверхні вузлів транспортних засобів. Методологія. Достовірність отриманих результатів і висновків забезпечено застосуванням низки методів наукового пізнання. Зокрема, діалектико-матеріалістичним методом з'ясовано об'єкт, предмет, мету і завдання дослідження в контексті поєднання здобутків технічних наук і потреб юридичної практики, коли виникають проблеми з визначення номерів вузлів транспортних засобів; системно-структурним методом класифіковано об’єкти дослідження; структурно-функціональним методом вивчено механізм розподілу магнітних силових ліній за наявності поверхневих і заглиблених дефектів; експериментальним методом доведено ефективність запропонованого пристрою. Наукова новизна. Розроблено і запроваджено в практику пристрій для магнітно-порошкової дефектоскопії номерів вузлів транспортних засобів. Отримано кількісний критерій оцінки його ефективності. Виснов$\boldsymbol{\kappa} \boldsymbol{u}$. Створено нову конструкцію та обгрунтовано параметри пристрою для магнітно-порошкової дефектоскопії номерних знаків вузлів транспортних засобів, який не складний і технологічний у виготовленні, а також у порівнянні з аналогами недорогий. Результати експертних досліджень 3 виявлення прихованих дефектів структури поверхневого шару металу за допомогою запропонованого пристрою засвідчили його працездатність при встановленні наявності перебивання номерних знаків, внесення інших цифр у зміст першопочаткового ідентифікаційного номера кузова або відсутності таких пошкоджень на поверхні вузлів транспортних засобів.
\end{abstract}

Ключові слова: пристрій; конструктивні параметри; магнітна дефектоскопія; магнітно-порошкова дефектоскопія; пошкодження поверхні; номерні знаки. 


\section{Вступ}

Експертиза номерів транспортних засобів, коли виникли проблеми з визначенням номерних позначень двигуна, кузова, в обов'язковому порядку проводиться в сервісному центрі МВС. Така потреба може постати під час техогляду транспортного засобу, державної реєстрації (перереєстраціі), зняття з обліку, якщо є труднощі при читанні номерів вузлів транспортних засобів (Novikov, Shilov, Kushner, \& Islevskii, 2019). Причин цього чимало, проте найпоширеніша - пошкодження цифр і ржа. Транспортні засоби після кількох років експлуатації піддаються корозії. Вплив агресивного навколишнього середовища позначається й на стані номерів.

Одним з ефективних і швидких методів експертних досліджень є магнітна дефектоскопія - метод неруйнівного контролю якості феромагнітних матеріалів і виробів (деталей) із них (Gorkunov, Povolotckaia, \& Zadvorkin, 2018). Заснований він на відшукуванні прихованих волосовин, пор, тріщин, раковин тощо за допомогою фіксації спотворення магнітного поля, що виникає в місцях таких дефектів у виробах із феромагнітних матеріалів (Tolmachev, 2008; Murashov, 2016). Застосовується (Troitskii, 2012) для виявлення порушень суцільності (тріщин, немагнітних включень й інших дефектів) у поверхневих шарах деталей із феромагнітних матеріалів і виявлення феромагнітних включень у деталях із неферомагнітних матеріалів; для контролю товщини немагнітних покриттів на деталях із феромагнітних матеріалів і товщини стінок тонкостінних деталей тощо.

У місцях порушення суцільності магнітний потік перерозподіляється. Різко змінюється характер розсіювання магнітного поля, що визначається величиною і формою дефекту, глибиною його залягання, а також його орієнтацією щодо напрямку магнітного потоку. Суть магнітної дефектоскопії як методу - фіксація спотворення магнітного поля на поверхні деталі над дефектом, що всередині, під час проходження магнітного потоку крізь деталь (Troitskii, 2002). Оскільки там, де є дефект, магнітна проникність змінюється стрибком, магнітні силові лінії, огинаючи це місце, «видають» його положення. Дефекти під поверхнею завглибшки до 2 мм «виштовхують» магнітні силові лінії за межі поверхні деталі, утворюючи місцеве спотворення магнітного поля (рис. 1).

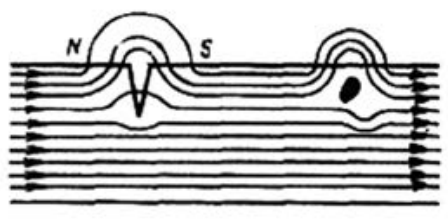

a

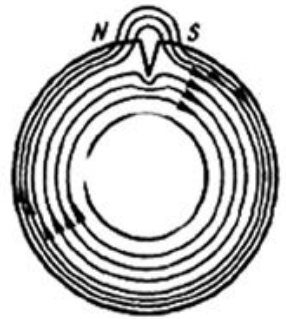

6

Рис. 1. Схеми розподілу магнітних силових ліній за наявності поверхневих і заглиблених дефектів: a - пласка поверхня; б - циліндрична поверхня

Розрізняють магнітно-порошковий і магнітно-люмінесцентний методи магнітної дефектоскопії. Найпоширеніший - магнітно-порошковий. При цьому на намагнічену деталь наносять магнітний порошок (сухий спосіб) або магнітну суспензію (мокрий спосіб). Частинки порошку, що потрапили в зону дії магнітних полів розсіювання, осідають на поверхні деталей над дефектом. Смуга осідання порошку значно ширша ніж розміри реального дефекту, тому невидимі до цього, наприклад, дуже вузькі тріщини фіксують за осілими частинками порошку навіть неозброєним оком. 
Доволі простий магнітно-порошковий метод дефектоскопії дає змогу визначати місця і контури несуцільності матеріалу на поверхні деталей, а також під поверхнею завглибшки до 2 мм. Намагнічують деталі, обробляють їх порошком (частіше суспензією), а також розмагнічують за допомогою магнітних дефектоскопів. За різного орієнтування дефектів провадять подвійний контроль із поздовжнім і циркулярним намагнічуванням. Більш продуктивний магнітно-порошковий контроль із використанням комбінованого намагнічування.

Чутливість магнітно-порошкового методу істотно залежить від ступеня намагніченості деталі під час оброблення магнітною суспензією (або порошком). У більшості випадків для магнітного контролю достатня залишкова намагніченість матеріалу деталей після їх намагнічування в тих чи інших магнітних полях. Але при контролі деталей із матеріалів з малою коерцитивною силою (маловуглецева сталь або сталь у відпаленому стані) залишкова намагніченість може бути недостатньою, навіть якщо йдеться про намагнічування в близьких до насичення магнітних полях. У цьому разі деталі слід обробляти суспензією або порошком під час дії магнітного поля, необхідного для створення потрібної намагніченості матеріалу. Такий вид контролю, на відміну від контролю способом залишкового намагнічування, називають контролем у доданому магнітному полі.

Виявлення дефектів залежить також і від їх геометричних параметрів. Краще виявляються дефекти на меншій глибині, що мають велику висоту і більше відношення висоти до ширини. Режими намагнічування обирають такі, щоб в кожному конкретному випадку добре виявлялися дефекти матеріалу. Про характер дефекту судять за осіданням магнітного порошку. Наприклад, тріщини (гартівні, кувальні й ін.) викликають щільне його осідання у вигляді різких ламаних ліній; волосовини - у вигляді прямих або злегка вигнутих (по волокну) тонких рисок, але інтенсивність осідання порошку менша за тріщини поперечних розрізів цих дефектів.

Для поліпшення видимості порошку його фарбують у контрастні до кольору контрольованих деталей кольори. Поряд зі звичайними червоно-коричневим і темно-сірим порошками, використовуваними під час контролю деталей зі світлою поверхнею, застосовують порошки світло-сірого, жовтого або зеленого кольорів для контролю деталей із темною поверхнею. Значно яскравіше вимальовуються дефекти, коли послуговуються магнітними порошками, частинки яких покриті шаром люмінофора (магнітно-люмінесцентна дефектоскопія).

Магнітно-порошковий дефектоскоп, що працює за методом неруйнівного контролю, використовують для виявлення поверхневих порушень магнітних металевих конструкцій і конструкцій із феромагнітних матеріалів. Якщо використання обладнання з електроживленням заборонено нормативними документами або в разі труднощів із його підведенням, дефектоскопи на постійних магнітах є єдиним приладом для проведення необхідних замірів (Troitskii, Bondarenko, \& Gorbik, 2007). Прилад являє собою два циліндричних корпуси, у кожному з яких магніти з різнополюсними значеннями з’єднані між собою гнучким магнітним проводом.

Магнітно-порошкова дефектоскопія не визначає втому металу, як коерцитиметри, проте дає змогу виявити практично всі види підповерхневих і поверхневих порушень досліджуваних виробів або поверхонь. Зокрема, після магнітно-порошкового контролю добре фіксуються волосовини, пори, тріщини, надриви, непроварювання зварних з’єднань. Магнітно-порошкові дефектоскопи для контролю зварних швів випускають серійно, але через конструкцію і габарити застосовувати їх під час контролю вуз- 
лів транспортних засобів, а також для виявлення прихованих дефектів номерів вузлів транспортних засобів незручно. До того ж і ціна цих приладів зависока.

\section{Мета і завдання дослідження}

Метою статті $є$ визначення конструктивних параметрів і працездатності пристрою для магнітно-порошкової дефектоскопії.

Для досягнення цієї мети необхідно виконати такі завдання:

створити конструкцію пристрою з обгрунтуванням нових конструктивних співвідношень для проведення експертних досліджень із виявлення прихованих дефектів структури поверхневого шару металу;

установити наявність перебивання номерних знаків, вварювання окремих ділянок або відсутності таких пошкоджень на поверхні вузлів транспортних засобів.

\section{Виклад основного матеріалу}

Проаналізуємо деякі конструкції пристроїв, призначених для виявлення прихованих дефектів структури поверхневого шару металу, з метою застосування їх для дефектоскопії номерних знаків вузлів транспортних засобів під час експертних досліджень.

Конструкція пристрою намагнічування для дефектоскопії - RF Patent № 2370761, 2009 (Fediukovich, 2009) складається із джерела магнітного поля, циліндричного магнітопроводу, на торцях якого полюсні наконечники, рукоятки для його переміщення. На загальній центральній вісі нерухомо встановлені: диск із немагнітного матеріалу; джерело магнітного поля у вигляді кільцевих постійних магнітів, що мають високу коерцитивну силу; циліндричний магнітопровід із двох однакових частин, які щільно контактують із постійним магнітом і становлять одне ціле з полюсними наконечниками у формі правильної багатогранної призми, кожен з яких має щонайменше п’ять граней. Рукоятка для переміщення пристрою у вигляді поворотного одноплечого важеля під прямим кутом до загальної центральної вісі містить вилку, виготовлену з немагнітного металу і шарнірно з'єднану із загальною центральною віссю. При цьому вилка забезпечена ексцентрично розміщеним опорним елементом, що уможливлює зчеплення з полюсним наконечником для його повороту навколо його осі.

Конструкція пристрою для магнітно-порошкового контролю - RF Patent № 2020466, 1994 (Shelikhov, 1994) передбачає два П-подібних електромагніти на ділянці, що контролюється. Коли їх підмикають до джерела змінного струму, утворюється магнітне поле. За розміщенням нанесеного магнітного порошку визначають наявність дефектів.

Пристрій - RF Patent № 2356042, 2009 (Pashagin, \& Shcherbinin, 2009), призначений для контролю виробів із феромагнітних металів для виявлення дефектів, складається із блока живлення, електромагнітів, індикаторного пакета і пласкої котушки в міжполюсному просторі, пружно закріпленої на торцях електромагніту. Пристрій, що намагнічує, розміщують з індикаторним пакетом на поверхні деталі, що контролюється. Впливають змінним магнітним полем. Визначають наявність дефекту візуальним контролем розміщення частинок індикатора в індикаторному пакеті з подальшим стиранням зображення. За наявності дефекту в зоні контролю додатково вимірюють електричний опір магнітної рідини за допомогою електричних контактів, установлених в індикаторному пакеті.

Основним недоліком цих пристроїв $є$ те, що їх конструктивна будова не дає можливості розміщувати і фіксувати їх у важкодоступних місцях, зокрема в транспортних засобах. 
Зважаючи на окреслене, було поставлено завдання розробити пристрій для магнітно-порошкової дефектоскопії номерів вузлів транспортних засобів, в якому нове конструктивне виконання забезпечує отримання якісного зображення дефектів поверхні розміщення номерних знаків вузлів транспортних засобів або їх відсутності з подальшою фотофіксацією цифровим апаратом і отриманням електронного зображення для його аналізу.

Запропоновано нову конструкцію пристрою для магнітно-порошкової дефектоскопії номерних знаків вузлів транспортних засобів - Patent for utility model № 137151 of Ukraine, 2019 (Narolskyi, Sych, Hanziuk, Kravchuk, \& Hordieiev, 2019). Цей пристрій (рис. 2 і 3) складається з циліндричного осердя (П-подібного типу), на якому встановлено з'єднані електропроводкою дві дротові котушки, що підключені через нормально розімкнуту кнопку та змінний опір до джерела постійного або змінного струму. Торці осердя скіснозрізані під кутом $20^{\circ}$ до осі осердя (перетин за $A-A$ ). Зважаючи на конструктивні особливості розміщення номерних знаків на поверхнях вузлів транспортних засобів та їх розмірів, визначено основні конструктивні параметри пристрою, що вибирають за умови:

де $D$ - діаметр осердя;

$$
D=20 \ldots 22, \mu \text {, }
$$

$$
L=2 D+110, M M,
$$

де $L$ - відстань від країв осердя;

$$
C=2,5 D, м \mu,
$$

де $C$ - відстань від крайки осердя до тория котушки;

$$
H=1,2 L, M M,
$$

де $H$ - габаритний розмір за висотою пристрою.

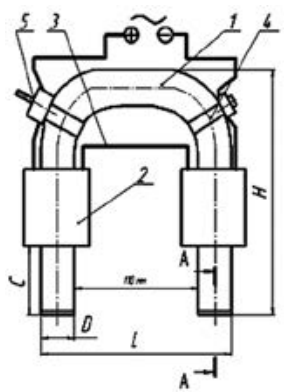

Рис. 2. Схема пристрою для магнітно-порошкової дефектоскопії та перетин за $A-A$ :

1 - циліндричне осердя; 2 - дротова котушка;

3 - електропроводка; 4 - нормально розімкнута кнопка; 5 - змінний опір

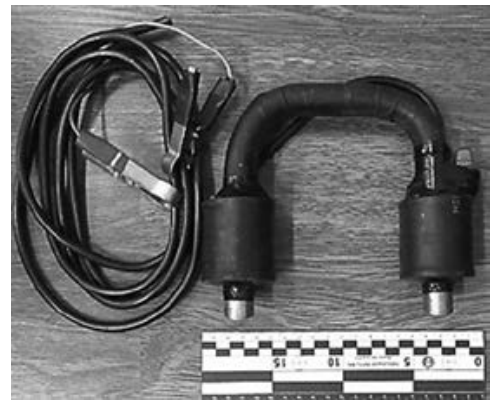

Рис. 3. Діючий пристрій для магнітно-порошкової дефектоскопії номерних знаків вузлів транспортних засобів

Працює пристрій так: за допомогою електропроводки (3) котушки (2) з'єднують із джерелом енергії (напруга 30 В постійного або змінного струму), наносять рідинний магнітний порошок на поверхню, що досліджується, і підводять пристрій із щільним контактом кінців осердя (1) до площини металевої поверхні, що контролюється, на- 
тискають кнопку (4), подаючи живлення на котушки (2) і створюючи замкнутий магнітний потік на поверхні, що досліджується. Коли на поверхні проявляються грубі пошкодження, створюють значний фон для виявлення менших пошкоджень, застосовуючи змінний опір (5) для пониження сили току на котушках.

Після того як відбулася фіксація (реєстрація) рідинним порошком, цифровим фотоапаратом фотографують вигляд поверхні розподілу магнітного порошку з подальшою передачею на персональний комп'ютер для створення електронного файлу.

Аналізуючи електронний файл вигляду поверхні розподілу магнітного порошку, визначають наявність дефектів. Торці осердя, що під кутом $20^{\circ}$ до осі осердя, дають змогу вводити пристрій у важкодоступні місця, при цьому не закриваючи П-подібним з’єднанням осердя вигляд поверхні розподілу магнітного порошку під час фотофіксації.

Таке технічне рішення (Narolskyi, Sych, Hanziuk, Kravchuk, \& Hordieiev, 2019) забезпечує можливість отримати якісне цифрове зображення вигляду поверхні, що контролюється, з конфігурацією розподілу магнітного порошку при фотофіксації для визначення наявності дефектів номерних знаків транспортних засобів або їх відсутності.

Працівники сектору КДТЗ Хмельницького НДЕКЦ МВС за допомогою запропонованого пристрою провели експертні дослідження номерних знаків різних вузлів транспортних засобів (рис. 4).

Серед отриманих результатів - установлення ознак порушення першопочаткового вигляду номерного знака (рис. 5-10), зокрема: перебивання цифр номерних знаків; виявлення ознак не заводського способу нанесення індивідуальних позначень окремих цифр номера двигуна; внесення інших цифр у зміст першопочаткового ідентифікаційного номера кузова.

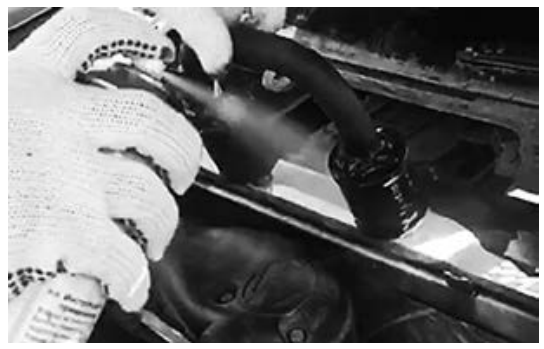

Рис. 4. Магнітно-порошкова дефектоскопія номерного знака транспортного засобу

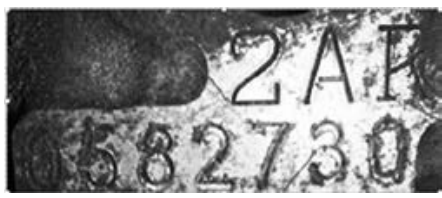

a
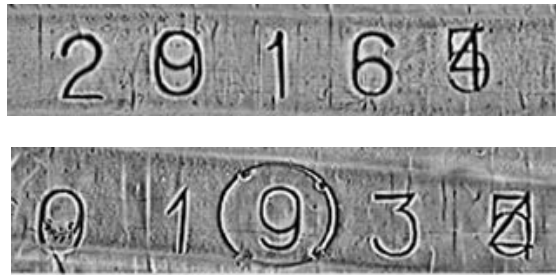

Рис. 5. Фотографія номерного знака з ознаками перебивання цифр

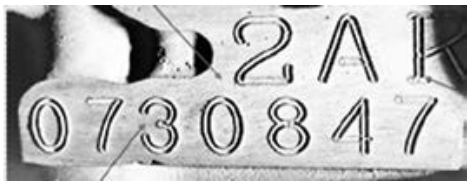

6

Рис. 6. Фотографія номерного знака з ознаками не заводського способу нанесення індивідуальних позначень окремих цифр номера двигуна: а - вигляд цифр заводського шрифту; $б$ - виявлення конфігурації цифр, що не відповідає заводському шрифту

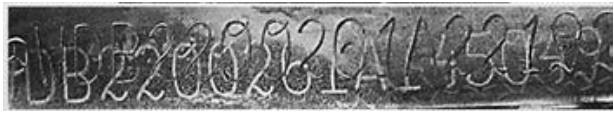

Рис. 7. Фотографія внесення інших цифр у зміст першопочаткового ідентифікаційного номера кузова 


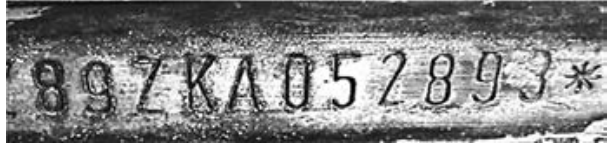

a

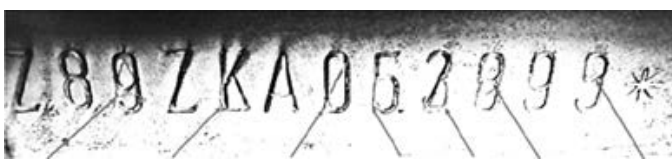

6

Рис. 8. Фотографія номерного знака:

а - фактичний вигляд; б - з ознаками цифр першопочаткового ідентифікаційного номера

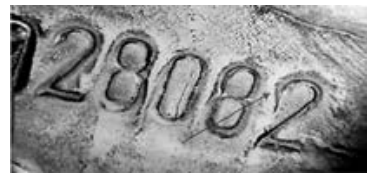

Рис. 9. Фотографія номерного знака з ознаками змін ідентифікаційних позначень цифр номера

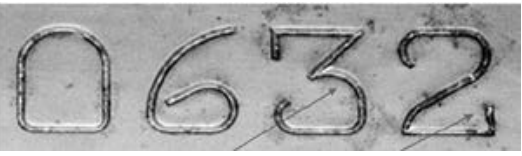

a

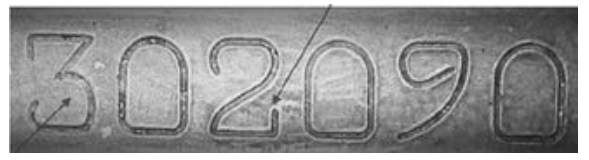

6

Рис. 10. Фотографія номерного знака з ознаками не заводського способу нанесення ідивідуальних позначень знаків номера кузова: а - вигляд цифр заводського шрифту;

6 - конфігурація цифр, що не відповідає заводському шрифту

При цьому слід наголосити, що перед застосуванням магнітно-порошкового методу дослідження ідентифікаційних позначень транспортних засобів із контрольованої поверхні для більш якісної візуалізації видаляють продукти корозії, залишки окалини, масляні забруднення, за необхідності сліди лакофарбових покриттів. У разі використання водної суспензії поверхню знежирюють. Для більш якісної візуалізації виявлених штрихів знака номера на поверхню номера наносять білий грунт.

Після дослідження номерних знаків транспортних засобів, щоб захисти їх від подальшого впливу агресивного зовнішнього середовища, поверхні обробляють методом цинкування із застосуванням пристрою «Цинкователь-1» (Ustroistvo «Tcinkovyvoditel-1»).

\section{Наукова новизна}

Розроблено і запроваджено в практику пристрій для магнітно-порошкової дефектоскопії номерів і вузлів транспортних засобів. Отримано кількісний критерій оцінки його ефективності.

\section{Висновки}

1. Створено нову конструкцію та обгрунтовано параметри пристрою для магнітно-порошкової дефектоскопії номерних знаків вузлів транспортних засобів, який не складний і технологічний у виготовленні, до того ж у порівнянні з аналогами недорогий.

2. Результати експертних досліджень із виявлення прихованих дефектів структури поверхневого шару металу за допомогою запропонованого пристрою засвідчили його працездатність при встановленні наявності перебивання номерних знаків, внесення інших цифр у зміст першопочаткового ідентифікаційного номера кузова або відсутності таких пошкоджень на поверхні вузлів транспортних засобів. 


\section{References}

Fediukovich, G. I. (2009). Patent RF 2370761. G01N27/84. Namagnichivaiushchee ustroistvo dlia defektoskopii; zaiavl. 04.10.08; opubl. 20.10.09. Biul. № 31 [in Russian].

Gorkunov, E. S., Povolotckaia, A. M., \& Zadvorkin, S. M. (2018). Raspredelenie magnitnogo potoka v ferromagnitnom materiale pri nalichii neferromagnitnogo zazora v sostavliaiushchei tcepi «pristavnoe magnitnoe ustroistvo-obekt». Defektoskopiia, 12, 41-49.

DOI: 10.1134/S0130308218120060 [in Russian].

Murashov, V. V. (2016). Otcenka stepeni nakopleniia mikropovrezhdenii struktury PKM v detaliakh i konstruktciiakh nerazrushaiushchimi metodami. Aviatcionnye materialy i tekhnologii, 3 (42), 73-81. DOI: 10.18577/2071-9140-2016-0-3-73-81 [in Russian].

Narolskyi, O. A., Sych, Ye. V., Hanziuk, A. L., Kravchuk, O. V., \& Hordieiev, A. I. (2019). Patent Ukrainy na korysnu model 137151. MPK H01F 13/00 (2006.01). Prystrii dlia mahnitno-poroshkovoi defektoskopii nomernykh znakiv vuzliv avtomobilnoi tekhniky; zaiavl. 13.03.19; opubl. 10.10.2019. Biul. № 19 [in Ukrainian].

Novikov, V. A., Shilov, A. V., Kushner, A. V., \& Islevskii, S. G. (2019). Obnaruzhenie izmenennykh nomerov kuzovov avtomobilei s pomoshchiu vizualiziruiushchei magnitnye polia plenki. Defektoskopiia, 3, 50-57. DOI: $10.1134 /$ S0130308219030096 [in Russian].

Pashagin, A. I., \& Shcherbinin, V. E. (2009). Patent RF 2356042. MPK9: G01N27/84, H01F13/00. Sposob magnitoporoshkovogo kontrolia i ustroistvo dlia ego osushchestvleniia; zaiavl. 09.24.07; opubl. 20.05.09 [in Russian].

Shelikhov, G. S. (1994). Patent RF 2020466. MPK9: G01N027/84. Sposob magnitno-poroshkovogo kontrolia; zaiavl. 06.10.92; opubl. 30.09.94. Biul. № 11 [in Russian].

Tolmachev, I. I. (2008). Fizicheskie osnovy i tekhnologiia magnitoporoshkovogo kontrolia: ucheb. posobie. Tomsk: Izdatelstvo Tomsk. politekh. un-ta. $125 \mathrm{~s}$. [in Russian].

Troitckii, V. A. (2002). Magnitoporoshkovyi kontrol svarnykh soedinenii i detalei mashin. Kiev: Feniks. 300 s. [in Russian].

Troitckii, V. A. (2012). Osnovnye tendentcii razvitiia nerazrushaiushchego kontrolia metallokonstruktcii. Tekhnicheskaia diagnostika i nerazrushaiushchii kontrol, 3, 67-71 [in Russian].

Troitckii, V. A., Bondarenko, A. I., \& Gorbik, V. M. (2007). Osobennosti sozdaniia i primeneniia namagnichivaiushchikh ustroistv na postoiannykh magnitakh dlia magnitnoi defektoskopii. Tekhnicheskaia diagnostika $i$ nerazrushaiushchii kontrol, 3, 26-32 [in Russian].

Ustroistvo «Tcinkovyvoditel-1». Vziato iz http:/vk.com/sinkovka [in Russian].

\section{Список використаних джерел}

Федюкович, Г. И. (2009). Патент РФ 2370761. G01N27/84. Намагничивающее устройство для дефектоскопии; заявл. 04.10.08; опубл. 20.10.09. Бюл. № 31.

Горкунов, Э. С., Поволоцкая, А. М., \& Задворкин, С. М. (2018). Распределение магнитного потока в ферромагнитном материале при наличии неферромагнитного зазора в составляющей цепи «приставное магнитное устройство-объект». Дефектоскопия, 12, 41-49.

DOI: $10.1134 / \mathrm{S} 0130308218120060$.

Мурашов, В. В. (2016). Оценка степени накопления микроповреждений структуры ПКМ в деталях и конструкциях неразрушающими методами. Авиационные материалы и технологии, 3 (42), 73-81. DOI: $10.18577 / 2071-9140-2016-0-3-73-81$.

Нарольський, О. А., Сич, Є. В., Ганзюк, А. Л., Кравчук, О. В., \& Гордєєв, А. І. (2019). Патент України на корисну модель 137151. МПК Н01F 13/00 (2006.01). Пристрій для магнітно-порошкової дефектоскопії номерних знаків вузлів автомобільної техніки; заявл. 13.03.19; опубл. 10.10.2019. Бюл. № 19.

Новиков, В. А., Шилов, А. В., Кушнер, А. В., \& Ислевский, С. Г. (2019). Обнаружение измененных номеров кузовов автомобилей с помощью визуализирующей магнитные поля пленки. Дефектоскопия, 3 , 50-57.

DOI: $10.1134 / S 0130308219030096$.

Пашагин, А. И., \& Щербинин, В. Е. (2009). Патент РФ 2356042. МПК9: G01N27/84, H01F13/00. Способ магнитопорошкового контроля и устройство для его осуществления; заявл. 09.24.07; опубл. 20.05.09.

Шелихов, Г. С. (1994). Патент РФ 2020466. МПК9: G01N027/84. Способ магнитно-порошкового контроля; 
заявл. 06.10.92; опубл. 30.09.94. Бюл. № 11.

Толмачев, И. И. (2008). Физические основы и технология магнитопорошкового контроля: учеб. пособие.

Томск: Издательство Томск. полит. ун-та. 125 с.

Троицкий, В. А. (2002). Магнитопорочковый контроль сварных соединений и деталей машин. Киев: Феникс. 300 с.

Троицкий, В. А. (2012). Основные тенденции развития неразрушающего контроля металлоконструкций. Техническая диагностика и неразрушающий контроль, 3, 67-71.

Троицкий, В. А., Бондаренко, А. И., \& Горбик, В. М. (2007). Особенности создания и применения намагничивающих устройств на постоянных магнитах для магнитной дефектоскопии. Техническая диагностика и неразрушающий контроль, 3, 26-32.

Устройство «Цинкователь-1». Взято из http:/vk.com/cinkovka.

Стаття надійшла до редакції 31.03.2020

\section{A. Hanzyuk, Ph.D (Technical Sciences),}

Head,

Khmelnitsky Scientific Research Forensic Center,

MIA of Ukraine, Khmelnytskyi, Ukraine

ORCID: https://orcid.org/ 0000-0003-3767-9427

A. Hordeev, DSc (Technical Sciences), Professor,

Specialist of the 1st category of the Activity Support Department,

Khmelnitsky Scientific Research Forensic Center, MIA of Ukraine,

Khmelnytskyi, Ukraine

ORCID: https://orcid.org/0000-0003-4494-4348

E. Sich, Head of the Automotive Research and

Forensic Investigation of Vehicles Department,

Khmelnitsky Scientific Research Forensic Center, MIA of Ukraine,

Khmelnytskyi, Ukraine

ORCID: https://orcid.org/ 0000-0002-0600-2766

\section{SUBSTANTIATION OF DEVICE DESIGN PARAMETERS FOR MAGNETIC-POWDER DEFECTOSCOPY OF VEHICLE NUMBER PLATES}

The purpose of the article is to substantiate the design parameters and performance of the device for expert research to identify hidden defects in the structure of the surface layer of metal and establish the presence of interruption of license plates, welding of individual areas or the absence of such damage to vehicle surfaces. Methodology. The reliability of the obtained results and conclusions is ensured by the application of a number of methods of scientific knowledge. In particular, the object, subject, goal and objectives of the research are established in the context of the achievements of technical sciences and the needs of legal practice using the dialectical-materialistic method, when problems arise in determining the node numbers of vehicles; system-structural objects of research are classified; the structural-functional method is used to study the distribution mechanism of magnetic lines of force in the presence of surface and buried defect; the experimental method proved the effectiveness of the proposed device. Scientific novelty. A device for magnetic-powder defectoscopy of vehicle node numbers was developed and put into practice. A quantitative criterion for evaluating its effectiveness is obtained. Conclusions. A new design has been created and the parameters of the device for magnetic-powder defectoscopy of license plates of vehicle components, not complicated and technologically advanced in manufacture, as well as in comparison with inexpensive analogues, have been substantiated. The results of expert studies to identify hidden defects in the structure of the surface layer of the metal with the proposed device proved its 
efficiency in detection of the redressing of license plates or the entering of other numbers into the contents of the initial identification number of the body or the absence of such damage on the surface of the nodes of vehicles.

Keywords: device; design parameters; magnetic defectoscopy; magnetic-powder defectoscopy; surface damage; vehicle number plates.

\title{
А. Л. Ганзюк, кандидат технических наук,
}

директор,

Хмельниикий научно-исследовательский

экспертно-криминалистический иентр МВД Украины, г. Хмельницкий

ORCID: https://orcid.org/ 0000-0003-3767-9427

А. И. Гордеев, доктор технических наук, профессор,

специалист 1-й категории отдела обеспечения деятельности,

Хмельницкий научно-исследовательский

экспертно-криминалистический центр МВД Украины,

2. Хмельницкий

ORCID: https://orcid.org/0000-0003-4494-4348

Е. В. Сыч, заведующий отделом автотехнических

исследований и криминалистического исследования

транспортных средств,

Хмельницкий научно-исследовательский

экспертно-криминалистический центр МВД Украины, г. Хмельницкий

ORCID: https://orcid.org/ 0000-0002-0600-2766

\section{ОБОСНОВАНИЕ ПАРАМЕТРОВ КОНСТРУКЦИИ УСТРОЙСТВА ДЛЯ МАГНИТНО-ПОРОШКОВОЙ ДЕФЕКТОСКОПИИ НОМЕРОВ ТРАНСПОРТНЫХ СРЕДСТВ}

\begin{abstract}
Целью статьи является обоснование конструктивных параметров и работоспособности устройства для экспертных исследований по выявлению скрытых дефектов структуры поверхностного слоя металла и установления наличия перебивки номерных знаков, вваривания отдельных участков или отсутствия таких повреждений на поверхности узлов транспортных средств. Методология. Достоверность полученных результатов и выводов обеспечена применением ряда методов научного познания. В частности, диалектико-материалистическим методом установлены объект, предмет, цель и задачи исследования в контексте достижений технических наук и потребностей юридической практики, когда возникают проблемы по определению номеров узлов транспортных средств; системно-структурным методом классифицированы объекты исследования; структурно-функциональным методом изучен механизм распределения магнитных силовых линий при наличии поверхностных и заглубленных дефектов; экспериментальным методом доказана эффективность предложенного устройства. Научная новизна. Разработано и внедрено в практику устройство для магнитно-порошковой дефектоскопии номеров узлов транспортных

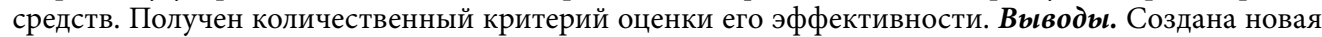
конструкция и обоснованы параметры устройства магнитно-порошковой дефектоскопии номерных знаков узлов транспортных средств, не сложного и технологичного в изготовлении, а также в сравнении с аналогами недорогого. Результаты экспертных исследований по выявлению скрытых дефектов структуры поверхностного слоя металла с помощью предлагаемого устройства показали его работоспособность при установлении наличия перебивки номерных знаков, внесения других цифр в содержание первоначального идентификационного номера кузова или отсутствия таких повреждений на поверхности узлов транспортных средств.
\end{abstract}

Ключевые слова: устройство; конструктивные параметры; магнитная дефектоскопия; магнитно-порошковая дефектоскопия; повреждения поверхности; номерные знаки. 